\section{BMJ Open}

Ophthalmology

\title{
Factors affecting the corneal endothelium after selective laser trabeculoplasty in primary open angle and angle closure glaucoma
}

\author{
Natalia Ivanovna Kurysheva (D) , Lyudmila Vyacheslavovna Lepeshkina, \\ Svetlana Georgievna Kapkova
}

To cite: Kurysheva NI, Lepeshkina LV, Kapkova SG. Factors affecting the corneal endothelium after selective laser trabeculoplasty in primary open angle and angle closure glaucoma. BMJ Open Ophthalmology 2021;6:e000638. doi:10.1136/ bmjophth-2020-000638

Received 15 October 2020 Revised 10 March 2021 Accepted 5 April 2021
Check for updates

C) Author(s) (or their employer(s)) 2021. Re-use permitted under CC BY-NC. No commercial re-use. See rights and permissions. Published by BMJ.

The Ophthalmological Center, Federal Medical and Biological Agency of the Russian Federation, Moscow, Russian Federation

Correspondence to Dr Natalia Ivanovna Kurysheva; e-natalia@list.ru

\section{ABSTRACT}

Purpose To study the factors affecting the corneal endothelium after selective laser trabeculoplasty (SLT) in primary open angle glaucoma (POAG) and primary angle closure glaucoma (PACG).

Method This prospective interventional study included 56 patients (56 eyes) with POAG and 55 patients (55 eyes) with PACG. All participants received a standard SLT session. Patients with PACG were pretreated with laser peripheral iridotomy for at least 2 months before SLT. Corneal endothelium cell count (ECC), pleomorphism and polymegathism were measured before SLT, as well as at the increments of 1 hour, 1 day, 1 week, 1 month, 3 months and 6 months following SLT using confocal microscopy. A multiple regression analysis was applied to detect the factors affecting the ECC in the long-term postSLT period.

Results In both groups, the mean ECC significantly decreased from the baseline after SLT. While in POAG, corneal endothelium recovered within 1 month, in PACG, its damage persisted throughout the whole follow-up period. According to the multiple analysis, baseline ECC $(\beta=0.891$, $p=0.000$ in POAG and $\beta=0.706, p=0.000$ in PACG) and age $(\beta=-0.227, p=0.000$ in POAG and $\beta=-0.196, p=0.000$ in PACG) were the common risk factors affecting ECC in both glaucoma forms, while the initial anterior chamber depth ( $\beta=0.254, p=0.000$ ), only in PACG. The duration of glaucoma treatment $(\beta=-0.317, p=0.043$ in POAG and $\beta=-0.302, p=0.047$ in PACG) and pigmented deposits on the corneal endothelium in PACG $(\beta=-0.326, p=0.019)$ were the risk factors determined in the univariate analysis. Conclusion Age and the baseline ECC are the risk factors for corneal endothelium damage after SLT in POAG and PACG. Shallow anterior chamber may affect corneal endothelium in PACG. These data should be considered when choosing an algorithm for glaucoma treatment.

\section{INTRODUCTION}

Selective laser trabeculoplasty (SLT) is a current method of hypotensive treatment of glaucoma, which has shown its high effectiveness as a first-line treatment of ocular hypertension and primary open angle glaucoma (POAG). ${ }^{1}$ Recent studies have demonstrated that this treatment method

\section{Significance of the study}

What is already known about this subject?

- Selective laser trabeculoplasty (SLT) may cause damage to corneal endothelium in primary open angle glaucoma (POAG), but this problem has not been studied in primary angle closure glaucoma (PACG).

\section{What are the new findings?}

- Age and the baseline endothelial cell count are the risk factors for corneal endothelium damage after SLT in POAG and PACG.

Shallow anterior chamber may affect corneal endothelium in PACG.

How might these results change the focus of research or clinical practice?

- These data should be considered when choosing an algorithm for glaucoma treatment and in researches comparing the laser treatment with clear lens/cataract extraction in PACG.

can be used in primary angle closure glaucoma (PACG) after yttrium aluminum garnet (YAG) laser peripheral iridotomy (LPI). ${ }^{2-4}$ This fact deserves special attention because even in the case of the opening of the anterior chamber angle (ACA) within a year after PI, $69 \%$ of the eyes need topical hypotensive therapy, and $31 \%$ need filtration surgery. ${ }^{5}$

Post-SLT permanent corneal changes are extremely rare, with only two reported cases. ${ }^{6}$ There have been a few reports on the post-SLT oedema of the central corneal stroma, haze and subsequent corneal thinning and scarring. ${ }^{7}$ In regard to this, much attention should be paid to the corneal endothelium.

The corneal endothelium is composed of a monolayer of hexagonal cells and plays a pivotal role in the homeostasis and hydration control of the cornea. Even though endothelial cell count (ECC) may be normal, the significant morphological changes may be 
present with respect to cells size/area (polymegathism) and shape/hexagonality (pleomorphism). This could be a reason for postoperative keratopathy with subsequent early and rapid corneal decompensation.

In our previous study, we reported on the early changes of the corneal endothelium cells in some patients with POAG after SLT. Our observations have shown that the maximum changes occur within an hour after SLT and are completely restored by the end of the first month after surgery. ${ }^{8}$ According to other authors, these changes persist for more than a month. ${ }^{9}$ In general, only a few studies on the ECC before and after SLT have been published. $^{9-13}$

Special attention should be paid to the corneal endothelium in PACG after SLT as it is preceded by LPI. The existing literature reports that LPI may have an adverse effect on corneal morphology. ${ }^{14}{ }^{15}$ Although other authors did not find this relation, ${ }^{16}$ it was noted though that PACG eyes, without and after PI, had a lower specular count compared with age-matched controls. ${ }^{17}$ According to Narayanaswamy et al, the ECC-reduced density persists up to 6 months after SLT in patients with PACG. ${ }^{3}$ The reasons for this are not yet known.

\section{Objective}

To study the factors affecting the corneal endothelium after SLT in PACG compared with POAG.

\section{MATERIALS AND METHODS}

The study included 55 eyes with PACG (mean age $68 \pm 7.9$ years) and 56 eyes with POAG (mean age $69 \pm 6.6$ years). The clinical study was conducted in accordance with the ethical principles specified in the World Medical Association Declaration of Helsinki and reflected in the Good Clinical Practice (GCP) and regulatory requirements. All patients each signed the authorised written informed consent form. The inclusion criteria for the first group were the elevated intraocular pressure (IOP) after a successful LPI for PACG in which trabecular meshwork (TM) was visible to gonioscopy without corneal indentation or manipulation and for a period of at least 2 months since PI. The second group included patients with POAG with the elevated IOP. The inclusion criteria included the patients with POAG, documented open angles with elevated IOP, and the medication naive or intolerant to glaucoma medications patients with elevated IOP.

The exclusion criteria were secondary angle closure glaucoma, any corneal pathology and patients who underwent glaucoma filtration surgery. The patients with a history of acute angle closure and secondary OAG were excluded as well as those having their fellow eye blind. If both eyes were eligible, only the right eye was included in the analysis.

All the patients were Caucasians. Patients or the public were not involved in the design, or conduct, or reporting or dissemination plans of our research.

The preoperative examination included autorefractometry, gonioscopy, optical coherence tomography
(OCT) with a measurement of the retinal nerve fibre layer (RNFL) thickness, OCT of the anterior segment with a measurement of ACA (Optovue Rtvue 100, California, USA), pachymetry (SP-100 Tomey, Germany) to determine the central corneal thickness (CCT), biometry (Lenstar LS 900, Haag-Streit Diagnostics, Switzerland), perimetry using Humphrey perimeter (Carl-Zeiss Meditec, Dublin, California, USA), SITA Standard 24-2 and biomicroscopy. IOP was examined using the ocular response analyser (Reichert, USA) prior to SLT, as well as after 1 hour, 1 day, 1 week, 1 month and 6 months after SLT. The iridocorneal angle was graded using the most detailed and recommended grading system of Spaeth. ${ }^{18}$ The angular approach was graded between $15^{\circ}-20^{\circ}$, $25^{\circ}-30^{\circ}$ and $35^{\circ}-50^{\circ}$. SLT in both groups was performed by one ophthalmologist (NIK). All eyes were pretreated with brimonidine tartrate $0.15 \%$ and pilocarpine hydrochloride $2.0 \%$ (if it was necessary in PACG eyes) prior to the procedure. $0.5 \%$ proximetacaine solution was used as a topical anaesthesia. SLT was performed using the Ellex Solo laser (Ellex Medical Laser, Adelaide, SA, Australia) in the SLT mode (Q-switched, frequency doubled Nd:YAG $532 \mathrm{~nm}, 3 \mathrm{~ns}$ pulse, spot size $400 \mathrm{~mm}$ with Latina SLT goniolens (Ocular Instruments, Bellevue, Washington, USA); the pulse energy varied from 0.6 to $1.2 \mathrm{~mJ}$ depending on the degree of trabecular pigmentation, the energy level was increased or decreased in $0.1 \mathrm{~mJ}$ steps until a minibubble formation was observed and this energy setting was used to complete the treatment. A total of 20-25 laser applications were applied to every quadrant of the visible TM. We avoid using alcohol for disinfecting SLT lenses since alcohol may cause superficial keratopathy and corneal oedema, which can potentially confound results on the corneal structure and function.

To prevent possible inflammation, all patients were prescribed topical non-steroidal anti-inflammatory drug - indomethacin $0.1 \%$ (Chauvin, UK) on the first day after SLT and for the first 3 days. Dorzolamide hydrochloride $2 \%$ was applied twice on the surgery day to prevent reactive hypertension in all eyes.

\section{Confocal microscopy}

The mean ECC in the central cornea, pleomorphism and polymegathism were evaluated using a non-contact specular mode of ConfoScan 4 (NIDEK, Japan). ConfoScan 4 with $\times 20$ probe images a wider field of view compared with other confocal systems and counts up to 1000 cells per examination with a scan depth set by default to 500 microns and a scan step set by default to 5 microns. Light shall be adjusted to $35 \%-40 \%$. The size of the studied area was $460 \times 345 \mu \mathrm{m}$, and the image size is $768 \times 576$. The lens $(\times 20)$ was at a distance of $12 \mathrm{~mm}$ from the patient's cornea. The microscope was aligned and focused on the corneal centre. As the automatic function of the machine captured the central endothelium, the cells were counted within the same area. The area for evaluation included at least 250 cells using semiautomated cell counting within the confocal microscope software. 


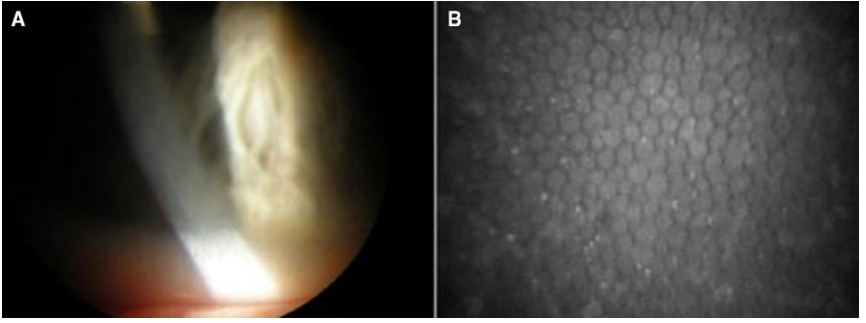

Figure 1 Pre-selective laser trabeculoplasty corneal endothelium in primary angle closure glaucoma 2 months after peripheral iridotomy. The multiple pigment deposits are visible on the surface of endothelium both in slit lamp examination $(A)$ and in micrograph of confocal microscopy (B).

The central corneal endothelial cell density was assessed and defined as the number of cells per $\mathrm{mm}^{2}$. Adequate tear film was ensured before each scan and the repeatability of measurements was confirmed.

The pleomorphism and polymegathism values were defined against normal values of $>59.0$ for pleomorphism and $<30.0 \%$ for polymegathism, which means that a normal healthy cornea should have at least $60 \%$ endothelial cells with a regular shape or hexagonality and should not have abnormal endothelial cell sizes or areas (normal 312-320 micron square) for more than $30 \%$ of cells. ${ }^{19}$ Special attention was paid to the presence of pigment deposits on the endothelium (figure 1).

\section{Statistical analysis}

The mean proportions were compared using the independent t-test and the $\chi^{2}$ test. The Spearman's test evaluated the correlation between ECC and pseudophakia, and between laser energy and CCT and corneal cell density. A simple linear regression analysis was performed to find the relation between ECC in 6 months and the risk factors. The following factors were assessed: age, ECC prior to SLT, ECC 1 month after SLT, anterior chamber depth, duration of glaucoma treatments and the presence of pigmented deposits on the corneal endothelium. The factors recognised as significant according to a simple linear regression analysis were subjected to a multiple regression analysis. Stepwise multiple linear regressions were used to determine the ECC determinants in 6 months using stepwise criteria of probabilityof-Fto-enter $<=0.05$, probability-of-F-to-remove $>=0.100$. Multicollinearity was checked using variance inflation factor. Within-group changes of cell density, as well as pleomorphism and polymegathism at different time points, were analysed using one-way repeated measures analysis of variance (ANOVA) and Mauchly's sphericity test. The Greenhouse-Geisser correction was applied, if sphericity was damaged. Post hoc test using the Bonferroni correction was used for pairwise comparisons. Between-group differences were compared by two-way repeated measures ANOVA. The numerical data are represented as the mean value \pm SD. Statistical processing of the obtained results was carried out using the standard package of statistical analysis software 'SPSS V.16.0 for Windows'. P value $<0.05$ was considered statistically significant.

\section{RESULTS}

The groups of patients with POAG and PACG were homogeneous in age, sex, number of hypotensive eye drops before SLT, RNFL thickness, perimetric parameters (MD and PSD), lens thickness and the degree of TM pigmentation. The groups were different in the axis length, the anterior chamber depth, and ACA and SLT parameters (table 1). Eighteen eyes in PACG and 22 eyes in POAG showed moderate irritation during the 24-hour period after SLT. Cornea and aqueous humour of the anterior chamber were transparent (a slight endothelial precipitation was present in one eye); the iris did not show hyperaemia; pupillary light response was intact; the fundus reflex was normal. Data on the postoperative IOP are given in table 1 .

The results of confocal microscopy are given in table 2 . The density and condition of cells prior to the surgery did not differ between the groups, except for the presence of pigment deposits that were observed in $12.5 \%$ of POAG eyes and in $40 \%$ of PACG eyes. The mean ECC showed a significant decrease from the SLT baseline in both groups, which was notable just 1 hour after SLT. More than a half of the post-SLT micrographs $(75.07 \%)$ made 1 hour later showed dark spots. The amount of these spots per micrograph varied from 0 to 9 in POAG and from 0 to 15 in PACG. Along with the decrease in cell density, the increase in their size and shape was noted. Figure 2 shows the clinical examples of the corneal endothelium changes in PACG compared with POAG in the patients of the same age and with the same glaucoma stage. In the absence of any differences before SLT, it is noticeable that the changes in PACG are more pronounced even an hour after the surgery, and these changes persist throughout the whole follow-up period. In POAG, on the contrary, corneal endothelium restoration occurs within a 1-month period after SLT.

According to table 2, all corneal endothelium parameters in POAG returned to the baseline 1 month after SLT, while they differed significantly from the baseline in PACG, even in 6 months after surgery. Thus, the cell density decreased in $76.3 \%$ of PACG eyes within 6 months after SLT and was significantly lower than in POAG. The same can be said about pleomorphism of endothelial cells, which remained significantly lower 6 months after SLT in PACG.

Polymegathism, on the other hand, significantly increased compared with the initial one, which indicates the ongoing active repair process aimed at restoring the density of the endothelial monolayer. ${ }^{20}$

There was a correlation between the corneal endothelium parameters and the laser exposure energy, which was more pronounced in PACG, since this correlation in PACG was observed both in early and distant periods after SLT (table 3). 
Table 1 Baseline characteristics of SLT-treated eyes in PACG and POAG

\begin{tabular}{|c|c|c|c|}
\hline Parameters & POAG & PACG & $P$ value \\
\hline Age, years & $69 \pm 6.6$ & $68 \pm 7.9$ & 0.492 \\
\hline Duration of glaucoma treatments before SLT, years & $4.92 \pm 1.76$ & $4.67 \pm 1.65$ & 0.534 \\
\hline Diabetes mellitus & $39.29 \%$ & $35.56 \%$ & 0.298 \\
\hline Pseudoexfoliation & $28.57 \%$ & $31.11 \%$ & 0.484 \\
\hline BCVA & $0.91 \pm 0.2$ & $0.85 \pm 0.18$ & 0.376 \\
\hline Central corneal thickness, $\mu \mathrm{m}$ & $550 \pm 26.96$ & $546 \pm 22$ & 0.547 \\
\hline Corneal hysteresis, $\mathrm{mm} \mathrm{Hg}$ & $9.53 \pm 1.44$ & $10.18 \pm 1.45$ & 0.238 \\
\hline Corneal resistance factor, $\mathrm{mm} \mathrm{Hg}$ & $10.53 \pm 2.04$ & $11.76 \pm 1.90$ & 0.204 \\
\hline Endothelial cell count (cells $/ \mathrm{mm}^{2}$ ) & $2473 \pm 177$ & $2436 \pm 171$ & 0.180 \\
\hline Mean energy used, mJ & $0.92 \pm 0.11$ & $0.88 \pm 0.09$ & 0.687 \\
\hline Angle pigmentation (0-3) & $2.1 \pm 0.75$ & $1.89 \pm 0.87$ & 0.630 \\
\hline Anterior-posterior axis, $\mathrm{mm}$ & $23.34 \pm 0.7$ & $22.93 \pm 1.46$ & 0.021 \\
\hline Anterior chamber depth, $\mathrm{mm}$ & $3.02 \pm 0.27$ & $2.72 \pm 0.29$ & 0.012 \\
\hline Baseline MD, dB & $-2.25 \pm 3.96$ & $-1.71 \pm 3.76$ & 0.291 \\
\hline Baseline PSD, dB & $4.62 \pm 4,06$ & $3.31 \pm 3.27$ & 0.763 \\
\hline Baseline RNFL, $\mu \mathrm{m}$ & $97.17 \pm 15.22$ & $98.54 \pm 16.16$ & 0.370 \\
\hline Dimensions of ACA upwards $\left({ }^{\circ}\right)$ & $24.67 \pm 6.64$ & $13.99 \pm 2.48$ & 0.003 \\
\hline Dimensions of ACA downwards $\left({ }^{\circ}\right)$ & $26.68 \pm 6.58$ & $23.45 \pm 6.21$ & 0.121 \\
\hline Pseudophakia, \% & $26.79 \%$ & $22.2 \%$ & 0.278 \\
\hline Baseline IOPcc, mm Hg & $23.28 \pm 3.67$ & $24.21 \pm 2.38$ & 0.363 \\
\hline IOPcc 1 hour after SLT, mm Hg & $19.44 \pm 7.13$ & $19.66 \pm 4.04$ & 0.651 \\
\hline IOPcc 24 hours after SLT, mm Hg & $15.62 \pm 3.47$ & $17.52 \pm 2.6$ & 0.135 \\
\hline IOPcc 1 week after SLT, mm Hg & $19.46 \pm 5.8$ & $18.38 \pm 2.03$ & 0.586 \\
\hline IOPcc 1 month after SLT, mm Hg & $18.56 \pm 3.27$ & $18.27 \pm 3.34$ & 0.928 \\
\hline IOPcc 6 months after SLT, mm Hg & $18.67 \pm 4.36$ & $18.92 \pm 3.49$ & 0.642 \\
\hline No of baseline antiglaucoma medications & $1.32 \pm 0.52$ & $1.26 \pm 0.6$ & 0.375 \\
\hline \multicolumn{4}{|l|}{ Type of hypotensive eye drops before SLT, \% } \\
\hline $\begin{array}{l}\text { Prostaglandin analogues (were switched to carbonic anhydrase } \\
\text { inhibitors } 3 \text { weeks before SLT) }\end{array}$ & $28.57 \%$ & $32.73 \%$ & 0.356 \\
\hline Carbonic anhydrase inhibitors & $19.64 \%$ & $25.45 \%$ & 0.189 \\
\hline Alpha-adrenergic agonists & $26.79 \%$ & $18.18 \%$ & 0.144 \\
\hline Beta-blockers & $14.29 \%$ & $14.55 \%$ & 0.942 \\
\hline No drops & $10.71 \%$ & $9.09 \%$ & 0.648 \\
\hline
\end{tabular}

ACA, anterior chamber angle; BCVA, Best Corrected Visual Acuit; IOPcc, corneal compensated intraocular pressure; PACG, primary angle closure glaucoma; POAG, primary open angle glaucoma; PSD, pattern standard deviation; RNFL, retinal nerve fiber layer; SLT, selective laser trabeculoplasty.

The results of the multiple regression analysis showed that the baseline ECG was the main factor affecting the endothelial cell count in the long-term period after SIT both in POAG, and in PACG, and this parameter was identified as a predictor in both univariate and multivariate analyses for both forms of glaucoma (table 4).

The longer duration of glaucoma treatment was detected as a risk factor of endothelium damage according to univariate analysis.

The age of patients was significant in both univariate and multivariate analyses for both glaucoma forms.
An inverse relation was noted between the density of endothelial cells before SLT and the presence of pseudophakia $(\mathrm{r}=-0.636, \mathrm{p}=0.000)$. This relation persisted even a month after SLT $(r=-0.695, p=0.000)$. Figure 3 shows that the ECC in pseudophakic eyes was lower than in phakic eyes.

Furthermore, the results of the present study have revealed the risk factors of the corneal endothelium damage which are typical only for PACG. They include the anterior chamber depth, which was determined as a risk factor in the multivariate analysis, and the presence 
Table 2 Confocal microscopy data in dynamics in SLT-treated glaucoma patients (Bonferroni corrected)

\begin{tabular}{|c|c|c|c|c|c|c|c|c|c|}
\hline & $\begin{array}{l}\text { Endothelial c } \\
\left(\text { cells } / \mathrm{mm}^{2}\right)\end{array}$ & $\begin{array}{l}\text { I count } \\
\mathrm{IM} \pm \mathrm{SE}\end{array}$ & & $\begin{array}{l}\text { Polymega } \\
\text { (normal is }\end{array}$ & $\begin{array}{l}n(\%) \\
0 \%) \\
\text { EMM }\end{array}$ & & $\begin{array}{l}\text { Pleomorph } \\
\text { (normal >5S }\end{array}$ & $\begin{array}{l}n(\%) \\
\%) \text { EMM } \pm \text { SE }\end{array}$ & \\
\hline & POAG & PACG & P value* & POAG & PACG & $\mathrm{P}$ valuet & POAG & PACG & $\mathrm{P}$ value \\
\hline $\begin{array}{l}\text { Prior to } \\
\text { SLT }\end{array}$ & $2458 \pm 21.1$ & $2438 \pm 21.8$ & 0.298 & $46.2 \pm 1.4$ & $43.2 \pm 1.3$ & 0.110 & $38.1 \pm 1.5$ & $39.1 \pm 1.5$ & 0.742 \\
\hline 1 hour after SLT & $\begin{array}{l}2301 \pm 20.0 \\
\mathrm{p} \dagger=0.000\end{array}$ & $\begin{array}{l}2269 \pm 16.9 \\
\mathrm{p} \dagger=0.000\end{array}$ & 0.000 & $\begin{array}{l}55.5 \pm 2.0 \\
\mathrm{p} \dagger=0.015\end{array}$ & $\begin{array}{l}49,0 \pm 1.5 \\
\mathrm{p} \dagger=0.028\end{array}$ & 0.010 & $\begin{array}{l}31.2 \pm 1.6 \\
\mathrm{p} \dagger=0.000\end{array}$ & $\begin{array}{l}34.1 \pm 1.5 \\
\mathrm{p} \dagger=0.018\end{array}$ & 0.242 \\
\hline 24 hours after SLT & $\begin{array}{l}2352 \pm 19.0 \\
\mathrm{p} \dagger=0000\end{array}$ & $\begin{array}{l}2271 \pm 30.3 \\
\mathrm{p} \dagger=0.000\end{array}$ & 0.000 & $\begin{array}{l}52.3 \pm 1.1 \\
\mathrm{p} \dagger=0.000\end{array}$ & $\begin{array}{l}46.1 \pm 2.0 \\
\mathrm{p} \dagger=0.048\end{array}$ & 0.016 & $\begin{array}{l}34.9 \pm 1.4 \\
\mathrm{p} \dagger=0.000\end{array}$ & $\begin{array}{l}33.9 \pm 1.6 \\
\mathrm{p} \dagger=0.001\end{array}$ & 0.934 \\
\hline 1 week after SLT & $\begin{array}{l}2403 \pm 14.5 \\
\mathrm{p} \dagger=0001\end{array}$ & $\begin{array}{l}2403 \pm 17.9 \\
\mathrm{p} \dagger=0.000\end{array}$ & 0.000 & $\begin{array}{l}49.5 \pm 1.0 \\
\mathrm{p} \dagger=0.001\end{array}$ & $\begin{array}{l}49.4 \pm 1.4 \\
\mathrm{p} \dagger=0.001\end{array}$ & 0.970 & $\begin{array}{l}35.1 \pm 1.1 \\
\mathrm{p} \dagger=0.023\end{array}$ & $\begin{array}{l}33.2 \pm 1.3 \\
\mathrm{p} \dagger=0.001\end{array}$ & 0.276 \\
\hline 1 month after SLT & $\begin{array}{l}2448 \pm 17.4 \\
\mathrm{p} \dagger=0.315\end{array}$ & $\begin{array}{l}2366 \pm 23.5 \\
\mathrm{p} \dagger=0.001\end{array}$ & 0.001 & $\begin{array}{l}44.4 \pm 1.1 \\
\mathrm{p} \dagger=0.321\end{array}$ & $\begin{array}{l}47.1 \pm 1.1 \\
\mathrm{p} \dagger=0.021\end{array}$ & 0.064 & $\begin{array}{l}41.2 \pm 1.3 \\
\mathrm{p} \dagger=0.255\end{array}$ & $\begin{array}{l}36.8 \pm 1.5 \\
\mathrm{p} \dagger=0.035\end{array}$ & 0.036 \\
\hline 6 months after SLT & $\begin{array}{l}2460 \pm 18.5 \\
\mathrm{p} \dagger=0.883\end{array}$ & $\begin{array}{l}2392 \pm 23.2 \\
\mathrm{p} \dagger=0.038\end{array}$ & 0.001 & $\begin{array}{l}44.1 \pm 1.3 \\
\mathrm{p} \dagger=0.482\end{array}$ & $\begin{array}{l}46.8 \pm 1.4 \\
p \dagger=0.045\end{array}$ & 0.082 & $\begin{array}{l}39.3 \pm 1.2 \\
\mathrm{p} \dagger=0.562\end{array}$ & $\begin{array}{l}35.2 \pm 1.1 \\
\mathrm{p} \dagger=0028\end{array}$ & 0.029 \\
\hline
\end{tabular}

${ }^{*} \mathrm{p}<0.05$ between the groups.

$\dagger \mathrm{p}<0.05$ compared with pretreatment parameter.

EMM, estimated marginal means.

of pigment deposits on the endothelium, although this clinical parameter was significant only in univariate analysis.

\section{DISCUSSION}

This is one of the few studies in the literature measuring ECCs, pleomorphism and polymegathism before and in the long-term period after SLT.

The obtained results have demonstrated the important role of the initial state of the endothelium: the lower the ECC is, the worse the prognosis at different post-SLT stages is. A significant reduction in the ECC within an hour after SLT was revealed. Thus, in PACG, the ECG decreased by $3.48 \%$ within the first month after SLT, while the normal age-related decrease in cell density is $0.6 \%$ per year. ${ }^{21}$ Since the relation between the decrease in cell density after SLT and age was observed in both glaucoma groups, it can be assumed that SLT has certain limitations for elderly patients with the initially low cell density.

To the best of our knowledge, this is the first study that has revealed that unlike POAG, when cell density, pleomorphism and polymegathism were completely restored by the end of the first month after SLT, the corneal endothelium changes in PACG persisted within 6 months after surgery. This may be due to the presence of pigment deposits on the corneal endothelium, which were observed almost in the half of PACG eyes (table 4).

The obtained results coincide with the observations of other authors. According to Ong et al, ${ }^{10}$ the cause of the corneal endothelium damage in SLT may be related to the pigment deposits on it that appeared after the previously performed laser or surgical intervention, when pigment deposits lead to better energy absorption by the corneal endothelium cells. As all patients with PACG in our study were first exposed to PI, this could lead to pigment deposits from the iris on the corneal endothelium, making it more vulnerable during subsequent laser interventions.

It should be noted that the literature on the SLT effect on corneal endothelium is usually very scarce and ambiguous, and refers only to POAG. Lee et al reported that $360^{\circ}$ SLT causes a short-term ECC reduction and the reduction of CCT within 1 week of SLT. ${ }^{11}$ White et al found that even $180^{\circ}$ SLT could cause transient endothelium changes but all these changes disappeared within 6 weeks after surgery. ${ }^{9}$

Many authors, including us at an earlier date, noted the appearance of dark spots resembling endothelium clefts within the first hours and days after SLT. ${ }^{8-11}$ This phenomenon may be explained by the transient reduction in cells possibly due to inflammatory cell attachment on the endothelium or cellular oedema separating the endothelial cells from the Descemet's membrane impairing their ECC. This inflammation is associated with the increase in corneal thickness due to oedema. According to the literature, the incidence of the post-SLT corneal oedema is rather low: approximately $0.8 \%$, however, according to Lee, it may be higher. ${ }^{11}$ As the results of our previous studies have shown, a significant increase in corneal thickness persists longer in the case of PACG compared with POAG, and this correlated with the energy of laser exposure during the first month after SLT in both forms of glaucoma. ${ }^{12}$

The results of this study demonstrate a greater dependence of the state of the corneal endothelium on the energy of laser exposure in the case of PACG in comparison with POAG. This is evidenced by the correlation between the SLT energy and pleomorphism/polymegatism in PACG even in the long term after SLT compared with POAG. The data obtained allow us to suggest that in the case of PACG after SLT, a more pronounced inflammatory reaction occurs than in POAG. As our previous studies have shown, by the end of the observation, corneal thickness 


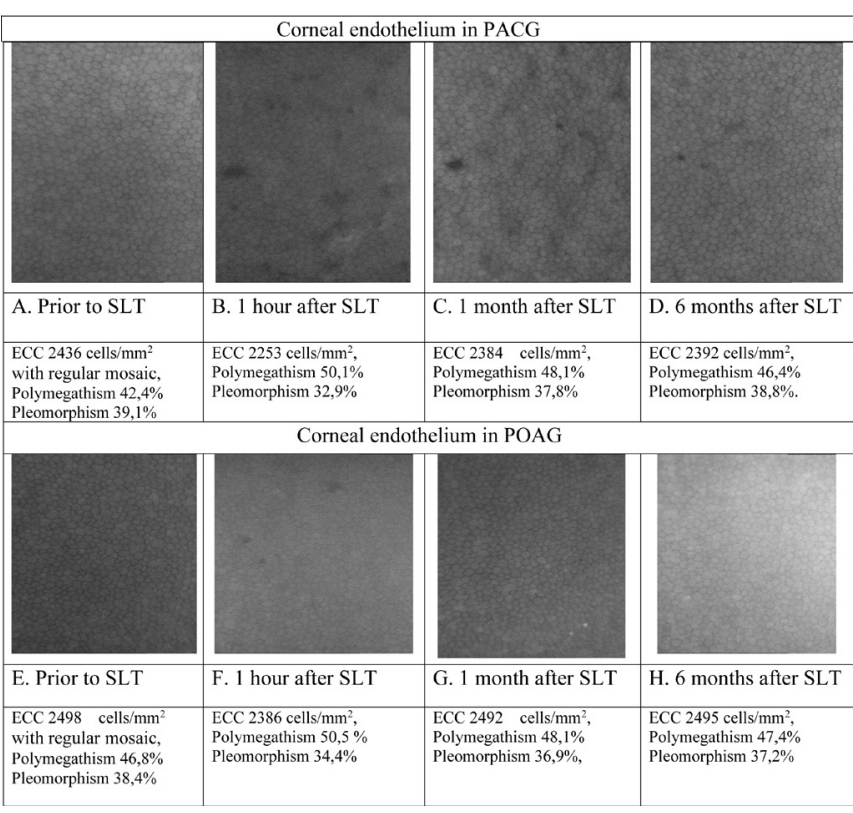

Figure 2 Micrographs of corneal endothelium in primary angle closure glaucoma (PACG) and primary open angle glaucoma (POAG) eyes pre-SLT and in post-term periods. The micrographs show the data on confocal microscopy of corneal endothelium of a patient aged 60-65 with PACG $(A-D)$ and a patient aged 65-70 with POAG $(E-H)$ before and after selective laser trabeculoplasty (SLT). Both eyes are phakic with the initial stage of glaucoma. SLT was performed in both cases. The anterior-posterior axis is 21.94 and 23.25 $\mathrm{mm}$ and the anterior chamber depth is 2.6 and $3.1 \mathrm{~mm}$ in PACG and POAG, respectively. The changes after SLT are noticeable in both cases, but they are more pronounced in PACG. Thus, an hour after SLT in the POAG eye, there are both small dark areas (1 cell or less in diameter) and larger dark areas (2 cells in diameter). In the PACG eye, there are numerous dark areas (2-4 cells in diameter) in all areas with a few dark areas (1 cell in diameter) (B). These changes still remained in 1 month after SLT (C) and even 6 months later. Polymegathism and pleomorphism remained abnormal (D). In the POAG eye, endothelial changes have regressed in 1 month and no dark areas are seen in the mosaic (G). Endothelium cell count (ECC), polymegathism and pleomorphism have achieved the baseline status $(H)$. returned to the baseline one. ${ }^{12}$ This indicates a return to normal functioning of the endothelial pump and endothelial permeability, which is necessary to restore the corneal stroma dehydrated during SLT.

SLT is a very gentle intervention method, which does not usually lead to any severe inflammation; nevertheless, SLT is known to increase the secretion of prostaglandins and cytokines in the anterior segment ${ }^{22}$ and to promote the formation of free oxygen radicals. ${ }^{23}$ Inflammatory mediators and free radicals increase the corneal endothelium permeability. ${ }^{24}$ In addition, the so-called 'champagne bubbles' formed during laser treatment can deposit on the endothelium and cause cell damage. ${ }^{9}$

The risk of adverse effect of SLT on the corneal endothelium may be increased in PACG. This is due to the predisposing anatomical factors. For example, a smaller anterior chamber than in POAG contributes to the formation of pigment deposits on the endothelium. In combination with other factors (age of patients, long glaucoma history), it can significantly worsen the prognosis concerning the condition of corneal endothelium in the long-term period (table 4). It is an interesting fact that the long-term existence of glaucoma before SLT was an unfavourable factor both in POAG and PACG, although it was established only using the univariate analysis. It can be assumed that this fact is related to the long-term use of topical hypotensive drops prior to SLT. They may have a cytotoxic effect on the corneal endothelium. ${ }^{25}{ }^{26}$ It should be noted that approximately a third of the patients in both groups used prostaglandin analogues (PGAs) before SLT. It was revealed that PGAs increase the inflammatory response in the anterior segment of the eye, which can reduce the reparative processes in the endothelium after SLT. ${ }^{27} 28$

It is worth noting that SLT in PACG can decrease IOP relative to the baseline in $60 \%$ compared with $84 \%$ after the treatment with PGAs. ${ }^{3}$ Narayanaswamy et al have reported that after 6 months following the procedure, IOP decreased by $4.0 \mathrm{~mm} \mathrm{Hg}$, on average, in the SLT group compared with $4.2 \mathrm{~mm} \mathrm{Hg}$ in the PGAs

Table 3 Correlation of pleomorphism and polymegatism of corneal endothelium with laser energies in SLT

\begin{tabular}{|c|c|c|c|c|}
\hline \multirow[b]{3}{*}{ Follow-up period } & \multicolumn{4}{|c|}{ Type of glaucoma } \\
\hline & \multicolumn{2}{|l|}{ PACG } & \multicolumn{2}{|l|}{ POAG } \\
\hline & Polymegatism & Pleomorphism & Polymegatism & Pleomorphism \\
\hline After 1 hour & - & - & - & - \\
\hline After 1 day & $\begin{array}{l}r=0.436 \\
p=0.020\end{array}$ & - & $\begin{array}{l}r=0.516 \\
p=0.003\end{array}$ & $\begin{array}{l}r=-0.441 \\
p=0.013\end{array}$ \\
\hline 1 week & $\begin{array}{l}r=0.458 \\
p=0.014\end{array}$ & $\begin{array}{l}r=-0.444 \\
p=0.018\end{array}$ & $\begin{array}{l}r=0.298 \\
p=0.018\end{array}$ & - \\
\hline 1 month & $\begin{array}{l}r=0.468 \\
p=0.012\end{array}$ & $\begin{array}{l}r=-0.528 \\
p=0.003\end{array}$ & - & - \\
\hline 6 months & $\begin{array}{l}r=0.402 \\
p=0.020\end{array}$ & $\begin{array}{l}r=-0.418 \\
p=0.046\end{array}$ & - & - \\
\hline
\end{tabular}

'-', no correlation was found. 


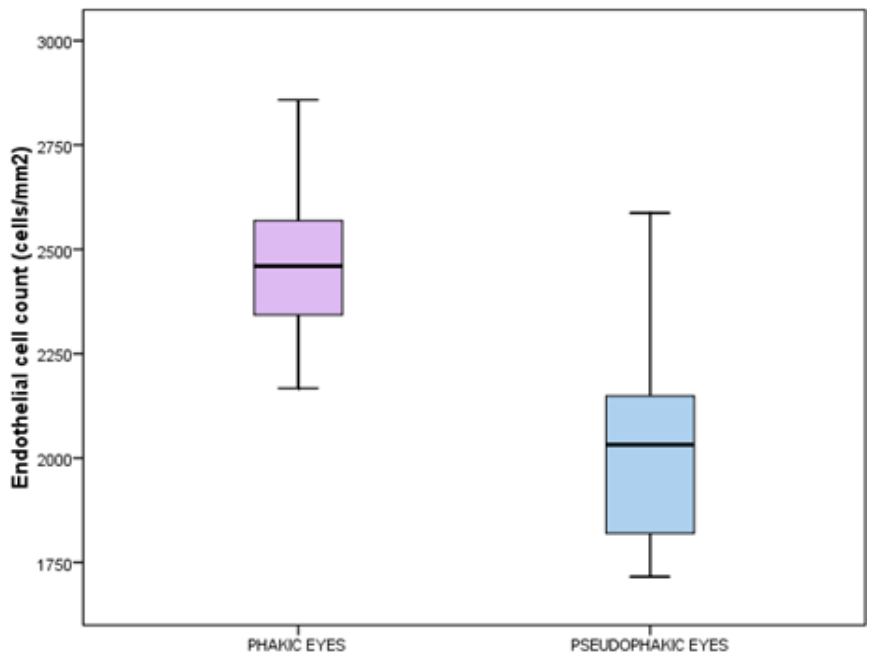

Figure 3 Box-and-whiskers plot demonstrating differences in the endothelial cell count (cells $/ \mathrm{mm}^{2}$ ) in phakic and pseudophakic eyes.

group ( $\mathrm{p}=0.78$ ), which amounted to $16.9 \%$ and $18.5 \%$, respectively $(\mathrm{p}=0.52)$. The authors concluded that the hypotensive effect of SLT in PACG after the previously performed LPI is comparable with the effect of the treatment with PGAs.

According to Ho et al, SLT reduces IOP by $20 \%$ without increasing the topical hypotensive regimen during the first 6 months after the procedure in almost $50 \%$ patients with PACG. ${ }^{2}$ Other authors have reported on the significant decrease in IOP in $84.7 \%$ in the PAC/PACG group and in $79.6 \%$ in the POAG group. ${ }^{4}$

In our previous study, we have observed the efficacy of SLT in PACG in the long-term period (6 years) that was comparable with SLT in POAG. ${ }^{29}$ Moreover, we have shown that SLT protects against glaucoma progression in the long term: it was revealed that SLT decreased the rate of structural deterioration by 1.4 times in PACG and by 1.5 times in POAG, and functional deterioration by 1.75 and 2.2 times in PACG and POAG, respectively. We explained this by a significant reduction of IOP after SLT. $^{30}$

However, we have noticed that the hypotensive effect of SLT depends on the initial anterior chamber depth ${ }^{12}$ : the dimensions of the anterior chamber less than 2.57 $\mathrm{mm}$ were considered as an unfavourable predictor of the SLT efficacy in PACG. ${ }^{29}$ The present study has revealed that the initially small anterior chamber is associated with the higher post-SLT risk of corneal endothelium damage. In this regard, and taking into account all these data, one may assume that early lens extraction may be more preferable method for the PACG patients with shallow anterior chamber.

Clear lens extraction itself decreases IOP in PACG and, according to recent studies, can be considered as a starting therapy for this form of glaucoma. ${ }^{31}$ On the other hand, the lens replacement surgery weakens the ability of the corneal endothelium to regenerate, ${ }^{32}$ especially in eyes with a smaller anterior chamber depth. ${ }^{33}$ 
According to the results of the study, the corneal endothelium density was significantly lower in pseudophakic eyes than in phakic ones. From this point of view, SLT can be considered as a method of treatment, which can be recommended as a preliminary stage of lens extraction in some patients with PACG. Based on the results of the multivariate analysis, this treatment method can be recommended for the PACG patients with a sufficient size of the anterior chamber, which can be achieved as a result of previously performed LPI. Thus, the present study allowed differentiating between the PACG patients that required SLT and cataract extraction.

The present study has several limitations that have to be considered. The first limitation is that the longterm period, when the last confocal microscopy was performed, is limited to 6 months. It can be assumed that the post-SLT corneal endothelium changes are delayed in nature, similarly to PI.

Thus, according to Canning et al, the endothelium changes after PI may occur 1 year after surgery ${ }^{34}$ which coincides with Kumar et al, who observed patients with PACG for 3 years after preventive PI. ${ }^{14}$ Park et al reported that corneal endothelial polymegathism remained within 2 years after surgery. ${ }^{35}$ This fact allows suggesting that the revealed slower recovery of the corneal endothelium in PACG as compared with POAG may cover the period longer than 6 months.

The second limitation is related to a small number of eyes with POAG and PACG that did not allow us to carry out a separate study of the patients with pseudophakia, as well as with pseudoexfoliative glaucoma. It can be assumed that these factors would be an additional aggravating factor for the corneal endothelium. ${ }^{32}$

The third limitation is that we did not consider the corneal endothelium thickness (CET); however, it is known that decreased CET-to-CCT ratio may indicate subclinical dysfunction of corneal endothelium. ${ }^{36}$

The strength of the study is the analysis of affecting factors. This analysis allowed improving the treatment algorithm and detecting a number of specific factors peculiar to PACG that should be taken into account in treating the patients with this form of glaucoma.

\section{CONCLUSION}

We have demonstrated that SLT may affect the corneal endothelium in POAG and PACG.

In both forms of glaucoma, unfavourable factors are older age and low baseline endothelial cell density. Shallow anterior chamber may affect corneal endothelium in PACG. These data should be considered when choosing an algorithm for glaucoma treatment.

Contributors NIK devised the project, the main conceptual ideas and proof outline. LVL was responsible for statistical data and performed the numerical calculations for the suggested experiment. SGK was responsible for technical details and analysis. NIK wrote the manuscript with input from all authors.

Funding The authors have not declared a specific grant for this research from any funding agency in the public, commercial or not-for-profit sectors.
Competing interests None declared.

Patient and public involvement Patients and/or the public were not involved in the design, or conduct, or reporting or dissemination plans of this research.

\section{Patient consent for publication Not required.}

Ethics approval The study was approved by the Institutional Review Board of the Federal Medical and Biological Agency (FMBA) of the Russian Federation and the A.I. Burnazyan Federal Medical and Biophysical Centre of FMBA.

Provenance and peer review Not commissioned; externally peer reviewed.

Data availability statement Data are available upon request.

Open access This is an open access article distributed in accordance with the Creative Commons Attribution Non Commercial (CC BY-NC 4.0) license, which permits others to distribute, remix, adapt, build upon this work non-commercially, and license their derivative works on different terms, provided the original work is properly cited, appropriate credit is given, any changes made indicated, and the use is non-commercial. See: http://creativecommons.org/licenses/by-nc/4.0/.

ORCID iD

Natalia Ivanovna Kurysheva http://orcid.org/0000-0002-2265-6671

\section{REFERENCES}

1 Gazzard G, Konstantakopoulou E, Garway-Heath D, et al. Selective laser trabeculoplasty versus eye drops for first-line treatment of ocular hypertension and glaucoma (light): a multicentre randomised controlled trial. Lancet 2019;393:1505-16.

2 Ho CL, Lai JSM, Aquino MV, et al. Selective laser trabeculoplasty for primary angle closure with persistently elevated intraocular pressure after iridotomy. J Glaucoma 2009;18:563-6. -.

3 Narayanaswamy A, Leung CK, Istiantoro DV, et al. Efficacy of selective laser trabeculoplasty in primary angle-closure glaucoma: a randomized clinical trial. JAMA Ophthalmol 2015;133:206-12.

4 Ali Aljasim L, Owaidhah O, Edward DP. Selective laser trabeculoplasty in primary angle-closure glaucoma after laser peripheral iridotomy: a case-control study. J Glaucoma 2016;25:e253-8.

5 Rosman M, Aung T, Ang LPK, et al. Chronic angle-closure with glaucomatous damage: long-term clinical course in a North American population and comparison with an Asian population. Ophthalmology 2002;109:2227-31.

6 Regina M, Bunya VY, Orlin SE, et al. Corneal edema and haze after selective laser trabeculoplasty. J Glaucoma 2011;20:327-9.

7 Moubayed SP, Hamid M, Choremis J, et al. An unusual finding of corneal edema complicating selective laser trabeculoplasty. Can J Ophthalmol 2009;44:337-8

8 Kurysheva N, Shatalova E, Polymegathism SE. Polymegathism, pleomorphism, and endothelial cell count after selective laser trabeculoplasty. Biol Med 2016;08:7.

9 White AJR, Mukherjee A, Hanspal I, et al. Acute transient corneal endothelial changes following selective laser trabeculoplasty. Clin Exp Ophthalmol 2013;41:435-41.

10 Ong K, Ong L. Selective laser trabeculoplasty may compromise corneas with pigment on endothelium. Clin Exp Ophthalmol 2013;41:109-10.

11 Lee JWY, Chan JCH, Chang RT, et al. Corneal changes after a single session of selective laser trabeculoplasty for open-angle glaucoma. Eye 2014;28:47-52.

12 Kurysheva NI, Lepeshkina LV. [Biomechanical properties of the cornea as predictors of the effectiveness of selective laser trabeculoplasty]. Vestn Oftalmol 2020;136:17-2.

13 Atalay K, Kirgiz A, Serefoglu Cabuk K, et al. Corneal topographic alterations after selective laser trabeculoplasty. Int Ophthalmol 2017;37:905-10.

14 Kumar RS, Baskaran M, Friedman DS, et al. Effect of prophylactic laser iridotomy on corneal endothelial cell density over 3 years in primary angle closure suspects. Br J Ophthalmol 2013;97:258-61.

15 Schwenn O, Sell F, Pfeiffer N, et al. Prophylactic Nd:YAG-laser iridotomy versus surgical iridectomy: a randomized, prospective study. Ger J Ophthalmol 1995;4:374-9.

16 Jamali H, Jahanian S, Gharebaghi R. Effects of laser peripheral iridotomy on corneal endothelial cell density and cell morphology in primary angle closure suspect subjects. J Ophthalmic Vis Res 2016;11:258-62.

17 Sihota R, Agarwal E, James M, et al. Long-Term Evaluation of Specular Microscopic Changes Following Nd:YAG Iridotomy in Chronic Primary Angle-Closure Glaucoma Eyes. J Glaucoma 2017;26:762-6. 
18 Spaeth GL. The normal development of the human anterior chamber angle: a new system of descriptive grading. Trans Ophthalmol Soc U K 1971;91:709-39.

19 Wali UK, Al-Mujaini AS, Al-Kharusi NS, et al. Quantitative and qualitative corneal endothelial morphology of Omani patients with pseudoexfoliation syndrome. Sultan Qaboos Univ Med J 2008;8:300-5.

20 Joyce N. Proliferative capacity of the corneal endothelium. Prog Retin Eye Res 2003;22:359-89.

21 Murphy C, Alvarado J, Juster R. Pre-Natal and post-natal cellularity of the human corneal endothelium. Invest Ophthalmol Vis Sci 1984;25:312-22.

22 Alvarado JA, Chau P, Wu J, et al. Profiling of cytokines secreted by conventional aqueous outflow pathway endothelial cells activated in vitro and ex vivo with laser irradiation. Invest Ophthalmol Vis Sci 2015;56:7100-8.

23 Guzey M, Vural H, Satici A, et al. Increase of free oxygen radicals in aqueous humour induced by selective Nd:YAG laser trabeculoplasty in the rabbit. Eur J Ophthalmol 2001;11:47-52.

24 Korenbrot $\mathrm{Jl}$. Ion transport in membranes: incorporation of biological ion-translocating proteins in model membrane systems. Annu Rev Physiol 1977;39:19-49.

25 Wu K-Y, Wang H-Z, Hong S-J. Cellular cytotoxicity of antiglaucoma drugs in cultured corneal endothelial cells. Kaohsiung J Med Sci 2007;23:105-11.

26 Ayaki M, Noda Y, Yaguchi S, et al. [Cytotoxicity of antiglaucoma ophthalmic solutions for human corneal endothelial cells]. Nippon Ganka Gakkai Zasshi 2009;113:576-82.

27 Song J, Yu D, Song A, et al. Corneal thinning and opacity following selective laser trabeculoplasty: a case report. $\mathrm{Br} J$ Med Med Res 2014;4:279-87.
28 Malvitte L, Montange T, Vejux A, et al. Measurement of inflammatory cytokines by multicytokine assay in tears of patients with glaucoma topically treated with chronic drugs. Br J Ophthalmol 2007;91:29-32.

29 Kurysheva NI, Lepeshkina LV, Shatalova EO. Predictors of outcome in selective laser trabeculoplasty: a long-term observation study in primary angle-closure glaucoma after laser peripheral iridotomy compared with primary open-angle glaucoma. J Glaucoma 2018;27:880-6.

30 Kurysheva NI, Lepeshkina LV. Selective laser trabeculoplasty protects glaucoma progression in the initial primary open-angle glaucoma and angle-closure glaucoma after laser peripheral iridotomy in the long term. Biomed Res Int 2019;2019:1-10.

31 Azuara-Blanco A, Burr J, Ramsay C, et al. Effectiveness of early lens extraction for the treatment of primary angle-closure glaucoma (Eagle): a randomised controlled trial. Lancet 2016;388:1389-97.

32 Feizi S. Corneal endothelial cell dysfunction: etiologies and management. Ther Adv Ophthalmol 2018;10:251584141881580.

33 Hwang HB, Lyu B, Yim HB, et al. Endothelial cell loss after phacoemulsification according to different anterior chamber depths. J Ophthalmol 2015;2015:1-7.

34 Canning CR, Capon MR, Sherrard ES, et al. Neodymium: YAG laser iridotomies--short-term comparison with capsulotomies and longterm follow-up. Graefes Arch Clin Exp Ophthalmol 1988;226:49-54.

35 Park H-YL, Lee NY, Park CK, et al. Long-term changes in endothelial cell counts after early phacoemulsification versus laser peripheral iridotomy using sequential argon:YAG laser technique in acute primary angle closure. Graefes Arch Clin Exp Ophthalmol 2012;250:1673-80.

36 Kulikov AN, Maltsev DS, Kudryashova EV, et al. Decreased epithelial to corneal thickness ratio in healthy fellow eyes of patients with unilateral bullous keratopathy. Br J Ophthalmol 2020;104:230-4. 